\title{
Health-related quality of life in children with and without chronic conditions. A multicenter study
}

\author{
Carolina Rivera, M.D. ${ }^{a}$, Verónica Mamondi, Master ${ }^{a}$, Julieta Lavin Fueyo, B.S. ${ }^{a}$, \\ Ezequiel Francisco Jouglard, Biochemist ${ }^{b}$, Lourdes Pogany, Anthropologist ${ }^{c}$, \\ María Camila Sánchez, M.D. ${ }^{d}$, Martina Prina, Anthropologistc, \\ Mariana Roizen, M.D. ${ }^{c}$, María Eugenia Esandi, M.D. ${ }^{b}$, and Silvina Berra, M.D. ${ }^{e}$
}

a. Center for Epidemiological Research and Health Services, Public Health School, Universidad Nacional de Córdoba.

b. Department of Health Sciences, Universidad Nacional del Sur. Hospital Militar Bahía Blanca, Bahía Blanca.

c. Hospital Nacional de Pediatría "Prof. Dr. Juan P. Garrahan", City of Buenos Aires.

d. Department of Pediatric Gastroenterology of Hospital Italiano de Buenos Aires, City of Buenos Aires.

e. CONICET. Center for Epidemiological Research and Health Services, Public Health School, Universidad Nacional de Córdoba. Argentina.

E-mail Address:

Carolina Rivera, M.D.: caro05rivera@yahoo. com.ar

Funding: This research study was conducted with the support of the "Ramón Carrillo-Arturo Oñativia" Scholarship Program (multicenter study), granted by the National Ministry of Health of Argentina through the Health Research Committee (Comisión Nacional Salud Investiga) in 2012, and the FONCYT PICT 20121173. The study in school children was partially funded by the Ministry of Science and Technology of the Province of Córdoba, PID 2010, Res. no. 000153/2011. Conflict of Interest:
None.

Received: 12-21-2014 Accepted: 4-22-2015

\begin{abstract}
Introduction. Chronic conditions (CCs) in the early stages of life may have an impact on various dimensions of health-related quality of life (HRQoL) in children.

Objective. To compare HRQoL in children with confirmed CCs, reported CCs, and without CC. Population and Method. Cross-sectional study conducted in 2012 in the context of a larger research study carried out at schools in Córdoba and Bahía Blanca, and at Hospital Italiano of Buenos Aires and Hospital Prof. Dr. Juan P. Garrahan at Buenos Aires. The presence of a chronic condition was established by medical diagnosis at the hospital or as reported by schoolchildren's caregivers. Eightto-twelve year-old children completed the KIDSCREEN-52 questionnaire on HRQoL, a pubertal development scale, and a family financial resource scale. The association between CCs and HRQoL adjusted by sex, age, pubertal development, maternal education level, and socioeconomic level was estimated.

Results. Six hundred and seventy children/ caregiver dyads participated; $13.3 \%(\mathrm{n}=89)$ had confirmedCCs, $14.5 \%(\mathrm{n}=97)$ wereschoolchildren with reported CCs, and the rest corresponded to healthy schoolchildren. Their average age was 10.2 years old (standard deviation $=1.01$ ); $54.8 \%$ were girls. Having a confirmed CC was associated with a higher frequency of low physical wellbeing (odds ratio [OR]: 2.61; 95\% confidence interval [95\% CI]:1.43-4.76), while the presence of a reported CC was associated with a low score in psychological well-being (OR: 1.96; 95\% CI: 1.06-3.63), self-perception (OR: 2.22; 95\% CI: 1.28-3.87), and parent relations (OR: 2.04; 95\% CI: 1.21-3.44).

Conclusions. Children with confirmed CCs showed a higher frequency of physical discomfort, and those with reported CCs showed discomfort in psychosocial areas compared to children without CCs.

Key words: health-related quality of life, children, schoolchildren, chronic conditions.
\end{abstract}

http:/ / dx.doi.org/10.5546/aap.2015.eng.404

\section{INTRODUCTION}

Chronic conditions (CCs) may have an impact on the ability to perform daily activities, cognitive development, emotions, self- perception, interpersonal relationships and relation with the environment. ${ }^{1}$

Health-related quality of life (HRQoL) allows to assess the impact of disease on daily life both at a subjective and at an overall level, and therefore provides multidimensional information on performance status and well-being, with a good correlation with pathophysiological indicators, ${ }^{2}$ regardless of the specific clinical manifestations of each disease, also including the individual's perspective. In addition, so-called generic instruments allow to compare healthy and sick groups, or groups with different diseases, ${ }^{3}$ and consider children with different health problems but who share the same experience.

Information obtained based on the perceptions of a child with CC is supplementary to traditional measures and its inclusion in decisiontaking is increasingly relevant. ${ }^{4}$

Previous studies have demonstrated that some perceived health dimensions are altered by the presence of a CC, while others do not suffer any impact, and this varies depending on the different diseases. The hypothesis of this study is that children with CCs will have a higher rate of lower scores in HRQoL than healthy children. The objective of this study was to compare HRQoL in children with confirmed CCs, reported CCs, and without $C C$.

\section{POPULATION AND METHODS}

Cross-sectional study conducted in 2012 at eight schools in the city of Córdoba and five schools in the city of Bahía Blanca, and at Hospital 
Italiano de Buenos Aires and Hospital Nacional de Pediatría "Dr. Prof. Juan P. Garrahan", at Buenos Aires, Argentina. In both hospitals, 8 to 12 year-old children attending the outpatient clinic for the management of asthma, juvenile idiopathic arthritis, type 1 diabetes mellitus, and inflammatory bowel disease diagnosed at least 6 months before study initiation were included; and all $4^{\text {th }}$ to $6^{\text {th }}$ grade schoolchildren from schools selected by convenience were invited to participate until reaching the desired sample size. Informed consent signature by the child's caregiver (mother, father or legal guardian), and the child's assent were inclusion criteria to be met. In addition, education authorities approved the study.

This study is the baseline phase of a longitudinal investigation with a sample made up of 472 healthy children and 95 children in each subgroup (confirmed CC and reported CC) conducted to analyze repeated group measures and to find 2-point differences in the mean HRQoL score by accepting an alpha risk of 0.05 and a beta risk of 0.2 in a two-tailed test. This sample size is sufficient to analyze the difference in means and associations using multivariate logistic regression models.

HRQoL was measured using the Argentine version $^{7,8}$ of the KIDSCREEN-52 questionnaire., ${ }^{9,10}$ This is a generic instrument that reports ten HRQoL dimensions: physical well-being, psychological well-being, moods and emotions, self-perception, autonomy, parent relations and home life, social support and peers, school environment, social acceptance, and financial resources.The KIDSCREEN-52 was adapted ${ }^{7}$ and subjected to reliability and validity studies ${ }^{8}$ in relation to the Argentine population. It provides a standard mean score of 50 and a standard deviation of 10 points; the score is then categorized as high or low, and a cut-off value of \pm 0.5 standard deviation of the reference mean is established. ${ }^{9}$

The presence of CC was confirmed based on medical records; the same diagnoses were included in both hospitals taking into account hospital departments' willingness to collaborate. At schools, caregivers were asked whether the child had had a chronic condition in the past 12 months, which had been diagnosed by a physician and for which treatment had been administered in the past year using a list of prevalent diseases: chronic allergy, asthma, bronchitis, diabetes, urinary tract infection, febrile seizures, epilepsy, malignancies, behavioral disorders and mental disorders. An open question was also included and reviewed in order to rule out acute conditions or symptoms. Children with the same conditions included in the hospital samples (for example, asthma) were not excluded. Based on this outcome measure, groups were divided into confirmed CC (children from hospitals), reported CC (schoolchildren) and without reported CC (schoolchildren) so as to compare HRQoL in children with reported and confirmed conditions, while healthy children comprised the reference group for both CC groups. Groups of children with CC differ when considering the source of information (confirmed medical diagnosis versus caregiver's report), prevalence and variety of diagnoses (defined as per inclusion criteria versus any reported diagnosis), and the extent of covered healthcare needs (under specific treatment versus various possibilities).

The Pubertal Development Scale (PBS) ${ }^{11}$ questionnaire was used as an indicator of pubertal development (PD) based on physical changes in sexual characteristics, which grants a score between 5 and 25. A higher score indicates a higher degree of development.

Family socioeconomic level (SEL) was measured by means of the Family Affluence Scale (FAS) $)^{12}$ using four questions on household material resources (number of cars and computers owned by the family, whether the child has his/her own room, and family vacations in the past year); the FAS score was categorized as low (score: 0-3), middle (score: 4-5), and high (score: 6-7).

Maternal education level (MEL) refers to the highest completed education level. MEL was categorized as per the International Standard Classification of Education (ISCED) as low (up to complete primary education), middle (complete secondary education), and high (complete tertiary or university education).

The questionnaire aimed at children asked on HRQoL, PD and SEL, while the one aimed at caregivers asked about relationship with the child, MEL and presence of CC in the child. At schools, children completed the questionnaire in the classroom using a self-administration approach guided by trained staff, while caregivers completed questionnaires at home. At hospitals, both questionnaires were administered during an interview at the waiting room. Questionnaires included other questions regarding employment 
characteristics and parent-reported HRQoL, but they were excluded from this study.

Absolute frequencies and percentages were calculated for data analysis. Mean scores for HRQoL dimensions were compared based on presence of CC; Bonferroni's correction for multiple comparisons was applied. The effect size was calculated to establish the size of such differences; values ranging from 0.20 to 0.50 were considered small effects, from 0.51 to 0.80 , moderate effects, and $>0.80$, large effects. Finally, the association between the presence of $\mathrm{CC}$ and HRQoL adjusted by sex, age, PD, MEL, and SEL was estimated using a multivariate logistic regression analysis. A value of $p<0.05$ was considered significant.

This study was conducted in the setting of a research study named "Longitudinal, multicenter study on health changes occurring between 8 and 12 years old from children's perspective". The protocol was approved by the Research Protocol Ethics Committee of Hospital Italiano de Buenos Aires, the Bioethics Institutional Board of Hospital Municipal de Agudos Dr. L. Lucero (city of Bahía Blanca), the Institutional
Ethics Committee on Child and Adult Health of Hospitalary District, province of Córdoba, and the Associate Department of Teaching and Research of Hospital de Pediatría Prof. Dr. Juan P. Garrahan at Buenos Aires.

\section{RESULTS}

The sample was made up of 670 children/ caregiver dyads; of these, $13.3 \%(n=89)$ had a confirmed CC, $14.5 \%(\mathrm{n}=97)$ had a reported CC, and $72.4 \%$ were schoolchildren without CCs. In most cases, mothers completed the questionnaire $(86.1 \%)$. Children were between 8 and 13 years old; their mean age was 10.2 years old, with a standard deviation of 1.01 year old. Girls accounted for $54.8 \%$ of participants. Mean degree of pubertal development was 9.08 among boys, and 9.34 among girls. A high economic status was observed in $65.9 \%$ of patients from Hospital Italiano, in $50.2 \%$ of schoolchildren from Bahía Blanca, in $40.9 \%$ of schoolchildren from Córdoba, and in 33\% of patients from Hospital Garrahan $(p=0.004)$ (Table 1). Less than half of caregivers had completed secondary or tertiary education.

The hospital sample was made up of 89

TABLE 1. Sample description by facility of origin

\begin{tabular}{|c|c|c|c|c|c|c|c|c|c|c|}
\hline & \multicolumn{2}{|c|}{$\begin{array}{l}\text { Schools in } \\
\text { Córdoba }\end{array}$} & \multicolumn{2}{|c|}{$\begin{array}{c}\text { Schools in } \\
\text { Bahía Blanca }\end{array}$} & \multicolumn{2}{|c|}{$\begin{array}{c}\text { Hospital } \\
\text { Italiano-CABA }\end{array}$} & \multicolumn{2}{|c|}{$\begin{array}{c}\text { Hospital } \\
\text { Garrahan-CABA }\end{array}$} & \multirow{2}{*}{$\begin{array}{c}\text { Total } \\
\mathrm{n}=670(\%)\end{array}$} & \multirow[t]{2}{*}{$\mathrm{p}^{*}$} \\
\hline & $\mathrm{n}=339$ & $(\%)$ & $\mathrm{n}=242$ & $(\%)$ & $\mathrm{n}=41$ & $(\%)$ & $\mathrm{n}=48$ & $(\%)$ & & \\
\hline \multicolumn{11}{|l|}{ Age } \\
\hline Mean score & 10.2 & & 10.2 & & 9.9 & & 9.9 & 10.2 & 0.031 & \\
\hline [SD] & {$[1.1]$} & & {$[0.9]$} & & {$[1.3]$} & & {$[2.3]$} & & {$[1.1]$} & \\
\hline \multicolumn{11}{|l|}{ Sex } \\
\hline Male & 163 & $(48.1)$ & 102 & $(42.1)$ & 18 & $(43.9)$ & 20 & $(41.7)$ & $303(45.2)$ & 0.509 \\
\hline Female & 176 & $(51.9)$ & 140 & (57.9) & 23 & $(56.1)$ & 28 & $(58.3)$ & $367(54.8)$ & \\
\hline \multicolumn{11}{|c|}{ Degree of pubertal development } \\
\hline Mean score & 9.2 & & 9.5 & & 7.2 & & 8.4 & & 9.2 & 0.009 \\
\hline [SD] & [3.3] & & {$[3.1]$} & & {$[3.4]$} & & {$[2.9]$} & & {$[3.2]$} & \\
\hline \multicolumn{11}{|c|}{ Chronic condition } \\
\hline Confirmed & 0 & & 0 & & 41 & $(100)$ & 48 & $(100)$ & $89(13.3)$ & \\
\hline Reported & 59 & $(17.4)$ & 38 & $(15.7)$ & 0 & & 0 & & $97(14.4)$ & \\
\hline Without CC & 280 & $(82.6)$ & 204 & $(84.3)$ & 0 & & 0 & & $484(72.4)$ & \\
\hline \multicolumn{11}{|c|}{ Economic status } \\
\hline Low & 56 & $(18.2)$ & 33 & $(13.8)$ & 1 & $(2.4)$ & 13 & $(27.1)$ & $103(16.2)$ & 0.004 \\
\hline Middle & 126 & $(40.9)$ & 86 & $(36)$ & 13 & $(31.7)$ & 19 & (39.6) & 244 (38.4) & \\
\hline High & 126 & $(40.9)$ & 120 & $(50.2)$ & 27 & $(65.9)$ & 16 & $(333)$ & $289(45.4)$ & \\
\hline \multicolumn{11}{|c|}{ Maternal education level } \\
\hline Low & 225 & $(67)$ & 108 & $(44.6)$ & 0 & & 32 & $(68.1)$ & 365 (54.8) & 0.001 \\
\hline Middle & 82 & $(24.4)$ & 86 & $(35.5)$ & 12 & $(29.3)$ & 9 & $(19.1)$ & $189(28.4)$ & \\
\hline High & 29 & $(8.6)$ & 48 & $(19.8)$ & 29 & $(70.7)$ & 6 & $(12.8)$ & $112(16.8)$ & \\
\hline
\end{tabular}

SD: standard deviation. CABA: Autonomous City of Buenos Aires.

* P value of chi square test and t-test for the comparison of group proportions and mean values, respectively. 
children, mostly from the asthma (39.3\%) and diabetes (29.2\%) groups. Among schoolchildren, 97 caregivers referred that children had one or more CCs; the most common CCs were chronic allergy $(28.7 \%)$ and pulmonary disease $(31.3 \%)$ (Table 2).

Children from hospitals had a worse physical well-being, but better moods and emotions, self-perception, school environment, and social acceptance than children without CCs $(p<0.05)$. Likewise, schoolchildren who stated having a CC showed a worse score in physical well-being, and also a worse psychological well-being, selfperception and autonomy when compared to their healthy peers $(p<0.05)$. The size of such differences was small, but statistically significant (Table 3).

As per the multivariate analysis, children with confirmed CCs had a higher frequency of low physical well-being (odds ratio [OR]: $2.61 ; 95 \%$ confidence interval [95\% CI]: 1.43-4.76) when compared to healthy children, while the presence of reported CCs was associated with a higher frequency of low scores in psychological wellbeing (OR: 1.96; 95\% CI: 1.06-3.63), self-perception (OR: 2.22; 95\% CI: 1.28-3.87), and parent relations and home life (OR: 2.04; 95\% CI: 1.21-3.44), when compared to schoolchildren without CCs (Table 4).

TABLE 2. Frequency of chronic conditions among schoolchildren and hospital samples

\begin{tabular}{lcc}
\hline Hospitals. Confirmed conditions: $\mathbf{n = 8 9}$ & $\mathbf{\%}$ & (n) \\
\hline Asthma & 39.3 & $(35)$ \\
Diabetes & 29.2 & $(26)$ \\
Arthritis & 19.1 & $(17)$ \\
Inflammatory bowel disease & 12.4 & $(11)$ \\
& & \\
Schools. Reported conditions: $\mathbf{n = 1 5 0 *}$ & $\mathbf{\%}$ & $\mathbf{( n )}$ \\
\hline Chronic allergy & 28.7 & $(43)$ \\
Recurrent bronchitis & 17.3 & $(26)$ \\
Asthma & 14 & $(21)$ \\
Urinary tract infection & 10 & $(15)$ \\
Behavioral disorders & 8.7 & $(13)$ \\
Mental disorders & 4 & $(6)$ \\
Epilepsy & 3.3 & $(5)$ \\
Gastrointestinal disorders & 2.7 & $(4)$ \\
Endocrine disorders & 2 & $(3)$ \\
Febrile seizures & 1.3 & $(2)$ \\
Diabetes & 0.7 & $(1)$ \\
Other chronic conditions & 7.3 & $(11)$ \\
\hline
\end{tabular}

* Among schoolchildren, 97 caregivers reported that children had one or more chronic conditions.

\section{DISCUSSION}

This study shows the differences in HRQoL among healthy children and those with CCs. Physical well-being and psychosocial dimensions of health were altered among children with longterm conditions.

Children with CCs had a worse physical well-being than healthy children, as observed in other studies; ${ }^{10,13}$ differences are more pronounced among children from hospitals. In a study considering physical CCs, all groups had a worse physical well-being and social functioning than healthy children, except for patients with diabetes, and a lower psychological health; the latter had the best scores. ${ }^{5}$

In addition, it is known than psychological well-being and self-perception are compromised among children with CCs. However, in a study that found differences in physical functioning between most groups of patients and healthy subjects in terms of social and psychological functioning, only some showed differences from the healthy group. ${ }^{14,15}$ In our study, schoolchildren with reported CCs showed a worse psychological well-being, self-perception, and parent relations and home life compared to healthy children. However, children from hospitals showed better moods and emotions, self-perception, school environment, and social acceptance than healthy children. Such differences are an interesting finding, since different CCs may have an impact on different HRQoL dimensions due to specific factors related to their condition and the care received.

Some special sample characteristics that may influence differences observed, such as sex and age, MEL and SEL, were adjusted for the multivariate analysis. However, there are probably other differences, for example, access to health services and treatments, that were not assessed in this study. In addition, children with CCs from hospitals may have scores that are higher than expected ${ }^{16}$ in relation to psychosocial dimensions as a result of their resilient attitude towards difficulties, since HRQoL is related with the meaning people attribute to life. In addition, a feeling of personal development associated with the experience, together with a qualitative and quantitative correlation, has been described among survivors of cancer and transplants. ${ }^{17}$ Such adaptability has also been suggested by some authors in relation to situations of inequality. ${ }^{18}$ 
In relation to this study's limitations, it is worth noting that the validity of classification by CC varies when it is reported or when it is diagnosed by a physician. However, reported CCs are recognized indicators of perceived needs in health service studies conducted using population surveys. Another limitation, which is inherent to the study's cross-sectional design, is that it is not possible to make causality assumptions between the presence of a CC and a low HRQoL. Recording variability over time in relation to the stage of the disease and the implications in social environment and family support ${ }^{19}$ children receive would probably allow to make a more profound analysis.

\section{CONCLUSIONS}

Children with confirmed CCs showed a higher frequency of physical discomfort, and those with reported CCs as reported by their caregivers showed discomfort in psychosocial areas compared to children without CCs.

\section{Acknowledgments}

The research team would mainly like to thank children and their mothers or caregivers for having agreed to participate in this study. Our work was facilitated by many authorities, healthcare providers, directors and teachers of the institutions where this field work was conducted: Hospital Italiano de Buenos Aires,

TABLE 3. Mean scores for health-related quality of life dimensions as per the presence of chronic conditions

\begin{tabular}{|c|c|c|c|c|c|}
\hline HRQoL dimensions & Chronic condition & n & M (SD) & $95 \%$ CI & $\begin{array}{c}\text { ES } \\
\text { (with CC vs. without CC) }\end{array}$ \\
\hline Physical well-being & $\begin{array}{c}\text { Confirmed } \\
\text { Reported } \\
\text { Without CC }\end{array}$ & $\begin{array}{c}88 \\
95 \\
456 \\
\end{array}$ & $\begin{array}{c}50.4(9.5) \\
50.3(10.3) \\
53.4(11.1) \\
\end{array}$ & $\begin{array}{l}48.4-52.4 \\
48.2-52.4 \\
52.4-54.4 \\
\end{array}$ & $\begin{array}{l}-0.28^{*} \\
-0.28^{*}\end{array}$ \\
\hline Psychological well-being & $\begin{array}{c}\text { Confirmed } \\
\text { Reported } \\
\text { Without CC }\end{array}$ & $\begin{array}{c}89 \\
96 \\
480 \\
\end{array}$ & $\begin{array}{c}56.8(9.0) \\
52.7(10.3) \\
56.3(9.2) \\
\end{array}$ & $\begin{array}{l}54.9-58.7 \\
50.6-54.8 \\
55.5-57.2 \\
\end{array}$ & $\begin{array}{c}0.05 \\
-\mathbf{0 . 3 8 *}\end{array}$ \\
\hline Moods and emotions & $\begin{array}{c}\text { Confirmed } \\
\text { Reported } \\
\text { Without CC }\end{array}$ & $\begin{array}{c}84 \\
93 \\
459 \\
\end{array}$ & $\begin{array}{l}51.8(10.1) \\
45.2(10.5) \\
47.0(10.6)\end{array}$ & $\begin{array}{l}49.6-53.9 \\
43.1-47.4 \\
46.1-48.0 \\
\end{array}$ & $\begin{array}{l}0.46^{*} \\
-0.17\end{array}$ \\
\hline Self-perception & $\begin{array}{c}\text { Confirmed } \\
\text { Reported } \\
\text { Without CC }\end{array}$ & $\begin{array}{c}88 \\
96 \\
474 \\
\end{array}$ & $\begin{array}{l}57.7(10.3) \\
50.9(10.5) \\
54.4(10.7) \\
\end{array}$ & $\begin{array}{l}55.5-59.9 \\
48.8-53.0 \\
53.4-55.3 \\
\end{array}$ & $\begin{array}{c}0.31^{*} \\
-0.33^{*}\end{array}$ \\
\hline Autonomy & $\begin{array}{c}\text { Confirmed } \\
\text { Reported } \\
\text { Without CC }\end{array}$ & $\begin{array}{c}89 \\
97 \\
478 \\
\end{array}$ & $\begin{array}{c}53.1(10.9) \\
48.9(10.0) \\
52.7(9.9) \\
\end{array}$ & $\begin{array}{l}50.8-55.4 \\
46.9-50.9 \\
51.8-53.6 \\
\end{array}$ & $\begin{array}{c}0.04 \\
-0.38^{*}\end{array}$ \\
\hline $\begin{array}{l}\text { Parent relations } \\
\text { and family life }\end{array}$ & $\begin{array}{c}\text { Confirmed } \\
\text { Reported } \\
\text { Without CC }\end{array}$ & $\begin{array}{c}87 \\
94 \\
471\end{array}$ & $\begin{array}{c}54.3(9.4) \\
49.8(10.7) \\
52.4(9.8)\end{array}$ & $\begin{array}{l}52.3-56.3 \\
47.6-52.0 \\
51.5-53.3\end{array}$ & $\begin{array}{l}0.19 \\
-0.26\end{array}$ \\
\hline Peers and social support & $\begin{array}{c}\text { Confirmed } \\
\text { Reported } \\
\text { Without CC }\end{array}$ & $\begin{array}{c}85 \\
96 \\
466 \\
\end{array}$ & $\begin{array}{l}56.8(12.2) \\
52.4(12.0) \\
54.1(11.7) \\
\end{array}$ & $\begin{array}{l}54.2-59.5 \\
50.0-54.8 \\
53.0-55.2 \\
\end{array}$ & $\begin{array}{c}0.23 \\
-0.14\end{array}$ \\
\hline School environment & $\begin{array}{c}\text { Confirmed } \\
\text { Reported } \\
\text { Without CC }\end{array}$ & $\begin{array}{c}86 \\
91 \\
465 \\
\end{array}$ & $\begin{array}{l}60.5(10.5) \\
55.7(11.9) \\
56.0(12.2)\end{array}$ & $\begin{array}{l}58.2-62.7 \\
53.2-58.2 \\
54.9-57.1 \\
\end{array}$ & $\begin{array}{l}0.38^{*} \\
-0.02\end{array}$ \\
\hline Social acceptance & $\begin{array}{c}\text { Confirmed } \\
\text { Reported } \\
\text { Without CC }\end{array}$ & $\begin{array}{c}89 \\
94 \\
473 \\
\end{array}$ & $\begin{array}{l}48.8(12.4) \\
42.8(12.4) \\
45.3(12.3)\end{array}$ & $\begin{array}{l}46.2-51.4 \\
40.3-45.4 \\
44.1-46.4 \\
\end{array}$ & $\begin{array}{l}0.28^{*} \\
-0.20\end{array}$ \\
\hline Financial resources & $\begin{array}{c}\text { Confirmed } \\
\text { Reported } \\
\text { Without CC }\end{array}$ & $\begin{array}{c}87 \\
96 \\
470\end{array}$ & $\begin{array}{l}49.4(9.1) \\
44.6(9.2) \\
47.1(9.4)\end{array}$ & $\begin{array}{l}47.4-51.3 \\
42.8-46.5 \\
46.2-47.9\end{array}$ & $\begin{array}{l}0.25 \\
-0.27\end{array}$ \\
\hline
\end{tabular}

M: mean; SD: standard deviation; CI: confidence interval; ES: effect size; HRQoL: health-related quality of life.

* Significant differences, Bonferroni's test $\mathrm{p}<0.05$. 
Hospital Garrahan, Sub-Department of Primary Education, Secretary of Education of Municipality of Córdoba, District Board of Education of Municipality of Bahía Blanca. To medical students of Universidad Nacional del Sur of Bahía Blanca: Estefanía Panizoni, Macarena Costabel, Ariani Priani, Luis Neculpán, Facundo Silveira and Sonia Ojeda, who helped with the field work.

\section{REFERENCES}

1. Solans M, Pane S, Estrada MD, Serra-Sutton V, et al. Health-related quality of life measurement in children and adolescents: a systematic review of generic and diseasespecific instruments. Value Health 2008;11(4):742-64.

2. AlonsoJ,FerrerM. Enfermedad pulmonarobstructivacrónica y salud percibida. Med Clin (Barc) 1998;111(15):580-2.
3. Alonso J. La medida de la calidad de vida relacionada con la salud en la investigación y la práctica clínica. Gac Sanit 2000;14(2):163-7.

4. Deshpande PR, Rajan S, Sudeepthi BL, Abdul Nazir CP. Patient-reported outcomes: A new era in clinical research. Perspect Clin Res 2011;2(4):137-44.

5. Varni JW, Limbers CA, Burwinkle TM. Impaired healthrelated quality of life in children and adolescents with chronic conditions: a comparative analysis of 10 disease clusters and 33 disease categories/severities utilizing the PedsQL ${ }^{\mathrm{TM}}$ 4.0 Generic CoreScales. Health Qual Life Outcomes 2007;5:43.

6. Sánchez C, Eymann A, De Cunto C, D'Agostino D. Quality of life in pediatric liver transplantation in a single-center in South America. Pediatr Transplant 2010;14(3):332-6.

7. Berra S, Bustingorry V, Henze C, Díaz MP, et al. Adaptación transcultural del cuestionario KIDSCREEN para medir la calidad de vida relacionada con la salud

TABLE 4. Odds ratio and 95\% confidence intervals for low scores in health-related quality of life dimensions as per the presence of chronic conditions

\begin{tabular}{|c|c|c|c|c|c|c|}
\hline \multirow[t]{2}{*}{ HRQoL dimensions } & \multirow[t]{2}{*}{ Chronic condition } & \multirow[b]{2}{*}{$\mathbf{n}$} & \multirow[b]{2}{*}{$\%$} & \multirow[t]{2}{*}{$\mathrm{OR}^{*}$} & \multicolumn{2}{|c|}{$95 \%$ CI } \\
\hline & & & & & LL & UL \\
\hline \multirow[t]{3}{*}{ Low score in physical well-being } & Confirmed & 25 & 41.0 & $2.61+$ & 1.43 & 4.76 \\
\hline & Reported & 23 & 29.9 & 1.35 & 0.77 & 2.36 \\
\hline & Without CC & 82 & 23.8 & 1 & & \\
\hline \multirow[t]{3}{*}{ Low score in psychological well-being } & Confirmed & 8 & 12.9 & 1.05 & 0.46 & 2.43 \\
\hline & Reported & 19 & 24.4 & $1.96+$ & 1.06 & 3.63 \\
\hline & Without CC & 50 & 14.0 & 1 & & \\
\hline \multirow[t]{3}{*}{ Low score in moods and emotions } & Confirmed & 22 & 38.6 & 0.66 & 0.36 & 1.20 \\
\hline & Reported & 46 & 61.3 & 1.34 & 0.80 & 2.26 \\
\hline & Without CC & 185 & 53.5 & 1 & & \\
\hline \multirow[t]{3}{*}{ Low score in self-perception } & Confirmed & 6 & 9.8 & 0.48 & 0.19 & 1.21 \\
\hline & Reported & 29 & 36.7 & $2.22+$ & 1.28 & 3.87 \\
\hline & Without CC & 69 & 19.4 & 1 & & \\
\hline \multirow[t]{3}{*}{ Low score in autonomy } & Confirmed & 22 & 35.5 & 1.73 & 0.95 & 3.15 \\
\hline & Reported & 30 & 38.0 & 1.62 & 0.97 & 2.73 \\
\hline & Without CC & 96 & 26.9 & 1 & & \\
\hline \multirow[t]{3}{*}{ Low score in parent relations } & Confirmed & 21 & 35.0 & 1.61 & 0.88 & 2.97 \\
\hline & Reported & 32 & 42.1 & $2.04 \dagger$ & 1.21 & 3.44 \\
\hline & Without CC & 97 & 25.9 & 1 & & \\
\hline \multirow[t]{3}{*}{ Low score in peers and social support } & Confirmed & 13 & 22.4 & 1.17 & 0.58 & 2.36 \\
\hline & Reported & 24 & 30.4 & 1.71 & 0.98 & 2.97 \\
\hline & Without CC & 70 & 20.0 & 1 & & \\
\hline \multirow[t]{3}{*}{ Low score in school environment } & Confirmed & 10 & 16.9 & 0.84 & 0.39 & 1.79 \\
\hline & Reported & 16 & 21.6 & 0.98 & 0.52 & 1.84 \\
\hline & Without CC & 78 & 22.4 & 1 & & \\
\hline \multirow[t]{3}{*}{ Low score in social acceptance } & Confirmed & 21 & 33.9 & 0.58 & 0.32 & 1.04 \\
\hline & Reported & 46 & 60.5 & 1.48 & 0.88 & 2.48 \\
\hline & Without CC & 180 & 50.6 & 1 & & \\
\hline \multirow[t]{3}{*}{ Low score in financial resources } & Confirmed & 24 & 39.3 & 0.88 & 0.94 & 1.56 \\
\hline & Reported & 42 & 53.8 & 1.61 & 0.97 & 2.67 \\
\hline & Without CC & 150 & 42.7 & 1 & & \\
\hline
\end{tabular}

${ }^{*} \mathrm{OR}$ : multivariate logistic regression analysis, adjusted by age, sex, pubertal development, maternal education level, and family economic status.

LL: lower limit. UL: upper limit.

HRQoL: health-related quality of life.

$+\mathrm{p}<0.05$. 
en población argentina de 8 a 18 años. Arch Argent Pediatr 2009;107(4):307-14.

8. Berra S, Tebé C, Esandi ME, Carignano C. Reliability and validity of the KIDSCREEN-52 questionnaire to measure health related quality of lifein the 8 to 18 year-old Argentinean population. Arch Argent Pediatr 2013;111(1):29-36.

9. The KIDSCREEN Group Europe. The KIDSCREEN Questionnaires. Quality of life questionnaires for children and adolescents. Lengerich: Pabst-Science; 2006.

10. Ravens-Sieberer U, Gosch A, Rajmil L, Erhart M, et al. The KIDSCREEN-52 quality of life measure for children and adolescents: psychometric results from a crosscultural survey in 13 European countries. Value Health 2008;11(4):645-58.

11. Bond L, Clements J, Bertalli N, Evans-Whipp T, et al. A comparison of self-reported puberty using the Pubertal Development Scale and the Sexual Maturation Scale in a school-based epidemiologic survey. J Adolesc 2006;29(5):709-20.

12. Currie CE, Elton RA, Todd J, Platt S. Indicators of socioeconomic status for adolescents: the WHO Health Behaviour in School-aged Children Survey. Health Educ Res 1997;12(3):385-97.

13. Tebe C, Berra S, Herdman M, Aymerich M, et al. Fiabilidad y validez de la versión española del KIDSCREEN- 52 para población infantil y adolescente. Med Clin (Barc) 2008;130(17):650-4.
14. Arnold R, Ranchor AV, Sanderman R, Kempen GI, et al. The relative contribution of domains of quality of life to overall quality of life for different chronic diseases. Qual Life Res 2004;13(5):883-96.

15. Békési A, Török S, Kökönyei G, Bokrétás I, et al. Healthrelated quality of life changes of children and adolescents with chronic disease after participation in therapeutic recreation camping program. Health Qual Life Outcomes 2011;9:43.

16. Payot A, Barrington KJ. The quality of life of young children and infants with chronic medical problems: review of the literature. Curr Probl Pediatr Adolesc Health Care 2011;41(4):91-101.

17. Roizen M. Calidad de vida relacionada con la salud en adultos jóvenes sobrevivientes de un trasplante hematopoyético alogénico en la infancia. Valuación a través de triangulación de métodos cuanti y cualitativos [abstract]. En: Sociedad Argentina de Hematología. XXI Congreso Argentino de Hematología; 29 de octubre al 1 de noviembre de 2013; Mar del Plata, Argentina.

18. Sen A. Capacidad y bienestar. En: Nussbaum MC, Sen A, compiladores. La calidad de vida. México DF: Fondo de Cultura Económica; 1998.Págs.54-83.

19. Sánchez C, Eymann A, De Cunto C. Health-related quality of life in children with chronic conditions lodged at a comprehensive accommodation in the City of Buenos Aires. Arch Argent Pediatr 2014;112(3):231-8. 